Зольникова Ю.Ф. Северо-Кавказский федеральный университет,

г. Ставрополь, Россия

zolnst@mail.ru

\title{
МЕДИКО-ХИМИЧЕСКИЕ ИССЛЕДОВАНИЯ ГИДРОМИНЕРАЛЬНЫХ РЕСУРСОВ РЕГИОНА КАВКАЗСКИЕ МИНЕРАЛЬНЫЕ ВОДЫ НА РУБЕЖЕ XVIII-XIX ВB.
}

Введение:

Материалы и методы:

Результаты исследования:

Кавказские Минеральные Воды (KMB) - это один из старейших курортных регионов России. Здесь, на сравнительно небольшой территории, сосредоточены значительные запасы 13 различных типов минеральныХ вод и лечебная иловая грязь. В XIX в. на базе рекреационных ресурсов региона возникли курорты мирового значения: Пятигорск, Кисловодск, Ессентуки и Железноводск. Постепенно в рекреационное использование региона вовлекались новые виды рекреационных ресурсов.

Исторический подход позволяет исследовать историю и особенности развития научных представлений о характере исследования гидроминеральных ресурсов регионаКавказских Минеральных Вод на каждом из этапов освоения курортного региона. Анализ исторических источников способствовал выявлению особенностей исследования гидроминеральных ресурсов с точки зрения использования их в лечебных целях, и определить вклад отдельных ученых в исследование минеральных источников региона.

Обобщены исследования врачей и химиков, работающих в регионе Кавказские Минеральные Воды на рубеже XVIII-XIX вв. В исследуемый период на Кавказских Минеральных Водах начинаются специализированные исследования гидроминеральных ресурсов с точки зрения использования их в лечебных целях. Проанализировано ряд научных работ, посвященных характеристике лечебного значения гидроминеральных ресурсов.

Обсуждение и заключения:

В результате исследований врачами и химиками гидроминеральных ресурсов региона Кавказские Минеральные Воды на рубеже XVIII-XIX вB. в курортный регион были назначены постоянные врачи и появляются проекты устройства источников.

Ключевые слова: Кавказские Минеральные Воды, гидроминеральные ресурсы, минеральные воды, рекреационные ресурсы, курорт 
Zolnikova Yu. F.

\section{MEDICAL AND CHEMICAL RESEARCHES OF HYDROMINERAL RESOURCES OF THE REGION CAUCASIAN MINERAL WATER AT THE TURN OF THE XVIII-XIX CENTURIES}

Introduction: $\quad$ Caucasian Mineral Waters (CMS) is one of the oldest resort regions of Russia. Here, in a relatively small area, considerable reserves of 13 different types of mineral waters and therapeutic mud are concentrated. In the XIX century. Resorts of world importance have emerged on the basis of the recreational resources of the region: Pyatigorsk, Kislovodsk, Yessentuki and Zheleznovodsk. Gradually, new types of recreational resources were involved in the recreational use of the region.

Materials and methods:

The historical approach allows us to explore the history and features of the development of scientific ideas about the nature of the study and the hydro-mineral resources of the Caucasian Mineral Waters region at each stage of the development of the resort region. The analysis of historical sources contributed to the identification of features of the study of hydromineral resources in terms of their use for medicinal purposes and to determine the contribution of individual scientists to the study of mineral sources in the region.

Research result:

The research of physicians and chemists working in the Caucasian Mineral Waters region at the turn of the XVIII-XIX centuries is summarized. In the study period, in the Caucasian Mineral Waters, specialized studies of hydromineral resources begin in terms of their use for medicinal purposes. Analyzed a number of scientific papers on the characteristics of the therapeutic value of hydromineral resources.

Discussion and conclusions:

As a result of research by doctors and chemists of the hydromineral resources of the region, the Caucasian Mineral Waters at the turn of the XVIII-XIX centuries. Permanent doctors were appointed to the resort region and projects of device sources appeared.

Keywords:

Caucasian Mineral Waters, hydro-mineral resources, mineral waters, recreational resources, resort 


\section{Введение}

Кавказские Минеральные Воды - один из старейших курортных регионов России, на территории которого сосредоточены разнообразные рекреационные ресурсы: гидроминеральные, грязевые, климатические и др.

Гидроминеральные ресурсы являются основным видом рекреационных ресурсов региона Кавказские Минеральные Воды. Богатые гидроминеральные ресурсы КМВ исследовались неравномерно. История развития рекреационной деятельности в регионе включает несколько этапов, отличающихся по характеру и особенностям исследования рекреационных ресурсов. Это связано с особенностями хозяйственного освоения и изменением потребностей российского общества в рекреационных услугах.

В лечебных целях гидроминеральные ресурсы региона Кавказских Минеральных Вод использовались еще в древности, первые описания появились в XIV в. (Ибн-Баттута). Первые русские сведения о Кавказских минеральных источниках содержатся в материалах XVII в., в частности, в «Книге Большому Чертежу», где упоминается о существовании в районе Пятигорья горячих источников: «...а по той реке земля Пятигорских черкасс, колодезь горячий» $[6,7$, c. 90$]$.

До начала XVIII в. представления о минеральных водах основывались на наблюдениях и практике людей, проживающих в районах выходов минеральных источников. Об их целебных свойствах судили на основе практического применения. С XVIII в. началось их изучение и освоение.

Для XVIII в. характерно стихийное освоение гидроминеральных ресурсов Кавказских Минеральных Вод. К концу XVIII в. интерес к этому региону значительно возрос, минеральные источники исследуемой территории все больше привлекают внимание как лечебные рекреационные ресурсы.

\section{Материалы и методы исследования}

В качестве источников использовались и анализировались научные труды и монографии исследователей Кавказских Минеральных Вод XIX-XX вв.:

А.П. Нелюбина,

Ф.А. Баталина,

О.А. Халецкого,

И.Я. Пантелеева и др.,

внесших большой вклад в изучение региона Кавказские

Минеральные Воды и обобщивших результаты исследований, которые про- 
водились отдельными исследователями на разных этапах становления и развития курортного региона. Изучены архивные материалы; акты, собранные Кавказской Археографической Комиссией, другие нормативные документы по отдельным городам-курортам региона Кавказские Минеральные Воды, в которых отражены результаты исследования гидроминеральных ресурсов региона в исследуемый период, а также приводятся сведения об особенностях изучения химического состава минеральных вод и использования их в лечебных целях. В результате, на основе разнообразного историко-географического материала, обобщены сведения, исследованы особенности изучения гидроминеральных ресурсов региона Кавказские Минеральные Воды на рубеже XVIII-XIX вв.

\title{
Результаты исследований и их обсуждение
}

К концу XVIII в. интерес к гидроминеральным ресурсам региона Кавказских Минеральных Вод значительно возрос, они приобретают интерес с точки зрения их медицинского значения. В этот же период минеральные источники стали интересовать и с точки зрения их химического состава и лечебных свойств, что отразилось на последующих исследованиях гидроминеральных ресурсов региона. В 90-е годы XVIII - начале XIX в. гидроминеральные ресурсы региона Кавказских Минеральных Вод исследуются с химической и медицинской точек зрения.

В 1798 г. по указанию Павла I было начато планомерное изучение гидроминеральных ресурсов Кавказских Минеральных Вод. В течение пяти лет этой проблемой занимались медики, аптекари и химики Медицинской коллегии:

\author{
Шателович П.И. (1797); \\ Левенц и Кернер (1798); \\ Симсен (1801); \\ Швенсон, Гординский П.А., Крушневич (1802).
}

По результатам их исследований был сделан вывод, что гидроминеральные ресурсы региона Кавказских Минеральных Вод «пользою своей не уступают некоторым из лучших иностранных, а некоторые превосходят» [11. С. 27].

В 1798 г. инспектор Астраханской врачебной управы П.И. Шателович, изучавший горячие источники КМВ, собрал интересные сведения о лечебном действии минеральных вод, основанные на обобщении народного опыта использования гидроминеральных ресурсов. И.П. Шателович предложил создать недалеко от Константиногорской крепости госпиталь для приезжих. 
В 1800 г. архитектор Александр Дигби, неоднократно посешавший Кавказские Минеральные Воды, учитывая предложения И.П. Шателовича, составил «План, прожектированный для построения каменного деревянного госпиталя на Кавказской линии близ Константиногорской крепости при самородных минеральных тепльх колодцах» [5]. Это был первый проект учреждения лечебной инфраструктуры на Горячих Водах [8]. Таким образом, с конца XVIII в. проводится планирование ряда инженерных мероприятий, необходимых для эффективной эксплуатации гидроминеральных ресурсов Кавказских Минеральных Вод.

В 1797 г. И.П. Шателович подал в Государственную Медицинскую коллегию доклад о целебных свойствах источника Нарзан. Уже в следующем 1798 г. о возможности лечебного использования минеральных вод с пользой для здоровья узнали больные солдаты и офицеры войск Кавказской линии. Об этом сообщили медики, которые были командированы на Кавказ. Вместе с тем, врачи, которые прописывали солдатам лечение минеральными водами еще до выхода соответствующих государственных распоряжений, жаловались на то, что свойства этих минеральных вод изучены очень слабо. Это было связано с отсутствием исследовательской базы для анализа гидроминеральных ресурсов. Таким образом, использовать минеральные воды военнослужащим рекомендовалось очень аккуратно и обязательно под наблюдением войсковых медиков [11].

В 1797 г. И.П. Шателович доложил медицинской комиссии «о некоторых действиях вод холодного источника, открытого в горах Кавказских от Константиногорской крепости к юго-западу в 35 верстах» [2. С. 930.].

В 1798 г. для изучения гидроминеральных ресурсов региона Кавказские Минеральные Воды были командированы штаб-лекарь Левенц и аптекарь Кернер. В представленном ими заключении отмечалось, что

«...из свойств найденных ими составных частей в воде можно уже несомнительно заключить, что она полезна во врачебном употреблении; но дабы еще более удостовериться в каких именно болезнях, каким образом употреблять ее и как определить точное ее действие и силу нужны долговременные опыты и наблюдения〉 (цит. по: [9. С. 7]). В результате из сделанного ими основательного описания были сделаны выводы, что «вода сего источника полезна во врачебном употреблении» [2. С. 930].

Последующие исследования Пятигорских минеральных вод и Кисловодского нарзана были произведены химиком Симсоном (1801), который разделил воды горячих источников по химическому составу. Но анализ, сделанный им, не сохранился [12]. 
В тот же период генералом от кавалерии Обрезковым были описаны все известные в то время минеральные источники региона Кавказские Минеральные Воды. На основании представленных им материалов в 1801 г. Медицинской коллегией было принято решение по отправке на Кавказские Минеральные Воды чиновника. Предполагалось, что он осмотрит местоположение минеральных источников, а также предоставит сведения о том, как правильно приспособить данную местность для лечения больных.

Таким образом, в 1802 г. для реализации поставленных задач на Кавказские Минеральные Воды были направлены врачи П.А. Гординский и Крушевич, а также аптекарь Швенсон.

Швенсон провел количественный анализ горячих сернистых источников Машука (Пятигорск) - было определено количество и состав газов и твердых частей [10]. П.А. Гординский и Крушневич в течение летнего сезона вели наблюдения за результатом действия минеральной воды при различных заболеваниях. Также ими было сделано первое измерение дебита горячего источника. Наиболее значимым результатом работ П.А. Гординского и Крушневича явилась сравнительная таблица, отражающая количество составных частей минеральных источников региона Кавказских Минеральных Вод и зарубежных минеральных вод [1]. По полноте и точности определения солевого состава эти анализы можно считать первыми в истории изучения химизма этих двух источников.

Таким образом, отчеты врачей П.А. Гординского и Крушневича, представленные в Медицинскую коллегию, включали описания гидроминеральных ресурсов (температура, вкус, вид, запах и др.), а также рекомендации по применению минеральных вод для лечения отдельных заболеваний. Нужно отметить, что наряду с результатами исследований минеральных вод, П.А. Гординский и Крушневич в своих отчетах предлагали и рекомендации по обустройству источников - постройке ванн, обустройству помещений для больных и военных - лазаретов, для облегчения больным использование минеральных вод. Также говорилось о назначении на Кавказские Минеральные Воды медицинских чиновников и т.д.

«... Для купанья больных сделать крытые и отдельные бассейны, а для прохаживания во время непогоды галерею. При источниках для больных всякого рода нужно учредить временные летние больницы и определить медицинских чинов и комиссара к усмотрению за строением и парками...» [1. Л. 10].

Исследовав свойства минеральных источников, а также местность, на которой расположены гидроминеральные ресурсы, чиновники медицинской комиссии сделали следующее заключение: «Горячий источник вытекает с высокого места, а на горе, хотя и есть две ванны, крытые и на- 
ружные, которые, однако, для много числа больных недостаточны, а другие в том месте сделать неудобно; при том некоторые больные по слабости и на гору входить не могут то не лучше бы было посредством труб привести воду от источника до подошвы горы, где сделать крытые ванны, для пола и состояния людей одна от другой отдельные» [11. С. 27].

Изучив все собранные материалы и предоставленные отчеты, Медицинская коллегия постановила, что «...по долговременном врачебном сих вод употреблении остается постановить правила, на опытах поставленные, дабы показать все способы врачевания., для чего нужно туда определить одного из опытнейших и искуснейших врача с жалованьем от 800 до 1000 руб., придав ему в помощь другого с жалованьем по 400 руб.» [11. С. 28], и представила правительству проект устройства курортов Кавказских Минеральных вод. Император ассигновал нужную сумму и определил на Кавказские Минеральные Воды врачей. При этом были определены обязанности назначенных врачей: изучение минеральных источников, определение всех «способов врачевания», а также врачебные консультации военнослужащим и частным лицам, приезжающим лечиться на КМВ. Постоянная заинтересованность Медицинской коллегии в исследовании и использовании источников Кавказских гидроминеральных ресурсов региона Кавказские Минеральные Воды свидетельствовала о том, что политика государства в отношении данной местности будет нести общегосударственный, а не региональный аспект.

Несмотря на начало специализированных исследований гидроминеральных ресурсов и первые научные результаты, Медицинская Коллегия не торопилась предпринимать какие-либо конкретные действия по обустройству Кавказских Минеральных Вод для последующего курортного использования. К обустройству источников региона стремились военные, находяшиеся на службе на Кавказе. В этот период они были основными потребителями гидроминеральных ресурсов Северного Кавказа. В ноябре 1800 г. генерал Кнорринг предложил Павлу I провести работу по благоустройству минеральных источников региона КМВ силами армии и за счет армии. При этом расходы на благоустройство проходили под статьей попечения о раненных и пострадавших в ходе войны с горцами. Таким образом, военное ведомство проявило инициативу, пытаясь добиться от правительства передачи региона Кавказских Минеральных Вод в свое непосредственное заведывание, видя в этом регионе в имеющихся здесь минеральных источниках лечебную базу для оздоровления раненых. Но Павел I допустить военных к делу курортного строительства на Кавказе отказался, отметив «...вспомоществование со стороны войск, для содержания сих колодцев надобные, не соответствуют той пользе, которую от них ожидать можно... сие решило Меня предписать предприятие сие впредь до удобного времени» [2. С. 734]. Кавказские Минеральные Воды остались в ведении Медицинской Коллегии. 


\section{Выводы}

Исследование гидроминеральных ресурсов региона Кавказские Минеральные Воды на рубеже XVIII-XIX вв. было связано с социально-экономическими условиями региона. Применение гидроминеральных ресурсов местными жителями в лечебных целях примитивным способом на рубеже XVIII-XIX вв. сменилось использованием их на основе научных методик первоначально для лечения военных. К началу XIX в. были накоплены уже определенные сведения о минеральных источниках региона Кавказских Минеральных Вод, были сделаны первые довольно подробные химические исследования известных минеральных вод (Пятигорских и Кисловодских), хотя и не всегда правильные. Параллельно изучалось и их лечебное действие на различные заболевания. Даются и первые рекомендации по обустройству вод - о строительстве ванн, лазаретов и др.

Таким образом, научное изучение гидроминеральных ресурсов района Кавказских Минеральных Вод началось в XVIII веке, и с тех пор интерес к этому району постоянно возрастал. Одним из факторов освоения гидроминеральной базы района был рост потребности населения России в лечебных услугах.

\section{Библиографических cmucok}

1. Выписка из представления медицинской коллегии и министру внутренних дел В.П. Кочубею о первых исследователях Кавказских минеральных Вод, целебных свойствах источников, строительстве ванн и домов при них // РГИА. Ф. 37. ОП. 11. Д. 116. Л. 10.

2. Высочайший рескрипт императора Павла I на имя генераллейтенанта К.Ф. Кнорринга от 15 декабря 1800 года «О неделании издержек и вспомоществования со стороны армии на благоустройство кавказских минеральных источников» // Акты, собранные Кавказской археографической комиссией. Архив Главного управления наместника Кавказского. Т. І. Тифлис, 1866. С. 734.

3. Представление Государственной Медицинской Коллегии министру внутренних дел графу В.П. Кочубею от 13 марта 1803 года «Об исследовании и курортном благоустройстве Кавказских Вод" // Акты, собранные Кавказской Археографической Комиссией. Архив Главного Управления Наместника Кавказского. Т. ІІ. Тифлис: Типография Управления Наместника Кавказского, 1868. С. 930-933.

4. Баталин Ф. А. Пятигорский край и Кавказские Минеральные Воды. СПб, 1861, ч. І-ІІ. 601 C. 
5. Боглачев С.В. Архитектура старого Пятигорска. Пятигорск: Снег, 2005.

6. Книга Большому Чертежу. М.; Л., 1950. 229.

7. Книга, глаголемая Большой Чертеж, изд. по поручению Императорского общества истории и древностей российских. М., 1846. $330 \mathrm{c}$.

8. Коваленко А.Н. В глубину веков (К 205-летию Кавказских Минеральных Вод) // Ставропольский хронограф на 2008 год. Краеведческий сборник. Ставрополь, 2008. С. 74-78.

9. Нелюбин А.П. Описание Кавказских Минеральных Вод. СПб., 1825. Ч. I,II. $672 \mathrm{c}$

10. Пантелеев И.Я. Очерк истории изучения и развития Кавказских Минеральных Вод. М., 1955. 204 с

11. Пятигорскв исторических документах 1803-1917 гг. Ставрополь, 1985. $352 \mathrm{c}$.

12. Халецкий О.А. Кавказские Минеральные Воды в медицинском отношении. СПб., 1883. Ч. І. Пятигорск, Железноводск. 375 с.

\section{References}

1. Extract from the presentation of the Medical College and the Minister of the Interior V.P. Kochubey about the first researchers of the Caucasian Mineral Waters, the healing properties of springs, the construction of baths and houses with them // RGIA. F. 37. Op. 11. D. 116. L. 10

2. The highest rescript of Emperor Paul I addressed to Lieutenant General KF Knorring dated December 15, 1800 «On the non-making of costs and assistance from the army for the improvement of the Caucasian mineral sources" // Acts collected by the Caucasian Archaeographic Commission. Archive of the Head Office of the Governor of the Caucasus. Volume I. Tiflis: Printing house of the Head Office of the Governor of the Caucasus, 1866. P. 734.

3. The presentation of the State Medical College to the Minister of Internal Affairs, Count VP Kochubey on March 13, 1803 «On the study and resort improvement of the Caucasian Waters» //Acts collected by the Caucasian Archaeographic Commission. Archive of the Head Office of the Governor of the Caucasus. Volume II. Tiflis: Printing house of the Governor of the Caucasus, 1868. P. 930-933.

4. Batalin, F. A., Pyatigorsk Territory and the Caucasian Mineral Waters. SPb, 1861, p. I-II. $601 \mathrm{c}$.

5. Boglachev S.V. The architecture of the old Pyatigorsk. Pyatigorsk: Snow, 2005.

6. Book to the Big Blueprint. M.; L., 1950. 229 p.

7. The book, the verb Big Drawing, ed. on behalf of the Imperial Society of Russian History and Antiquities. M., 1846. $330 \mathrm{p}$

8. Kovalenko A.N. In the depth of the centuries (To the 205th anniver- 
sary of the Caucasian Mineral Waters) // Stavropol chronograph for 2008. Local history collection. Stavropol, 2008. P. 74-78.

9. Nelyubin A.P. Description of the Caucasian Mineral Waters. SPb., 1825. Part I, II. $672 \mathrm{p}$

10. Panteleevl. Ya. Essay on the history of the study and development of the Caucasian Mineral Waters. M., 1955. 204 p.

11. Pyatigorsk in historical documents of 1803-1917. Stavropol, 1985 $352 \mathrm{p}$.

12. Khaletsky O.A. Caucasian Mineral Waters Medically. SPb., 1883 Part I. Pyatigorsk, Zheleznovodsk. 375 p.

Рукопись поступила в редакцию 28.04.19, принята к публикации 01.06.19

\section{O6 авторе}

Зольникова Юлия Федоровна, кандидат географических наук, доцент, доцент кафедры социально-экономической географии, геоинформатики и туризма Северо-Кавказскийфедеральный университет, ул. Пушкина, 1, к. 2, ауд. 120, Тел. (928) 631-88-30. E-mail: zolnst@mail.ru.

\section{About the author}

Zolnikova Yuliya Fedorovna, candidate of geographical Sciences, associate Professor, associate Professor of the Department of socio-economic geography, Geoinformatics and tourism North Caucasus Federal University, Pushkin str., 1, building 2, AUD. 120, Tel. (928) 631-8830. E-mail: zolnst@mail.ru. 